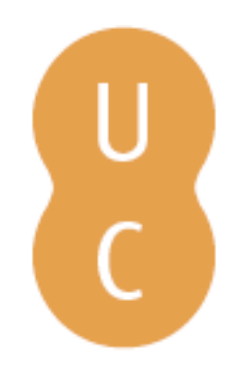

\title{
nommalina
}

\section{A reforma pombalina da Universidade, a Faculdade de Medicina e os estudos médicos e farmacêuticos}

\author{
Autor(es): $\quad$ Pita, João Rui \\ Publicado por: Imprensa da Universidade de Coimbra \\ URL \\ persistente: URI:http://hdl.handle.net/10316.2/32273 \\ DOI: $\quad$ DOI:http://dx.doi.org/10.14195/978-989-26-0413-8_6 \\ Accessed : $\quad$ 26-Apr-2023 16:06:42
}

A navegação consulta e descarregamento dos títulos inseridos nas Bibliotecas Digitais UC Digitalis, UC Pombalina e UC Impactum, pressupõem a aceitação plena e sem reservas dos Termos e Condições de Uso destas Bibliotecas Digitais, disponíveis em https://digitalis.uc.pt/pt-pt/termos.

Conforme exposto nos referidos Termos e Condições de Uso, o descarregamento de títulos de acesso restrito requer uma licença válida de autorização devendo o utilizador aceder ao(s) documento(s) a partir de um endereço de IP da instituição detentora da supramencionada licença.

Ao utilizador é apenas permitido o descarregamento para uso pessoal, pelo que o emprego do(s) título(s) descarregado(s) para outro fim, designadamente comercial, carece de autorização do respetivo autor ou editor da obra.

Na medida em que todas as obras da UC Digitalis se encontram protegidas pelo Código do Direito de Autor e Direitos Conexos e demais legislação aplicável, toda a cópia, parcial ou total, deste documento, nos casos em que é legalmente admitida, deverá conter ou fazer-se acompanhar por este aviso.

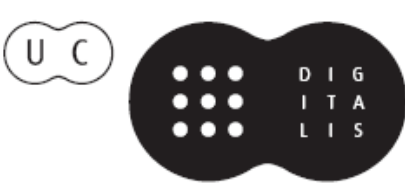


João Rui Pita

Coordenaçáo

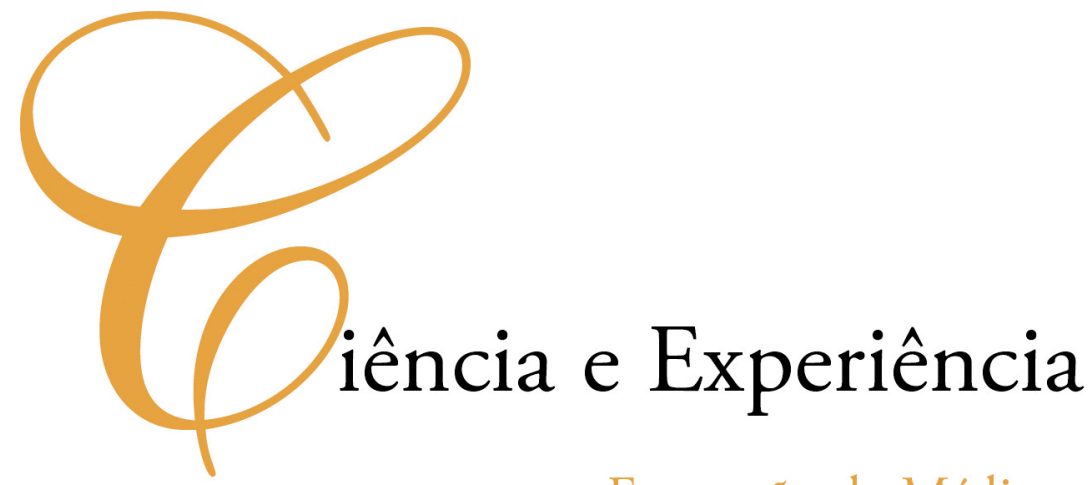

Formação de Médicos, Boticários, Naturalistas e Matemáticos

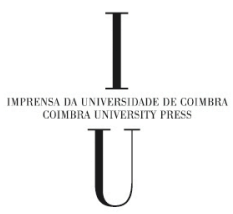

- COIMBRA 2006 
João Rui Pita

Faculdade de Farmácia da Universidade de Coimbra;

Centro de Estudos Interdisciplinares do Século XX da Universidade de Coimbra, CEIS2O

\section{A REFORMA POMBALINA DA UNIVERSIDADE, A FACULDADE DE MEDICINA E OS ESTUdOS MÉdicos E FARMACÊUTICOS}

O ensino foi uma das áreas onde a acção marcadamente reformista do Marquês de Pombal se fez sentir com maior intensidade. As suas decisões não passaram indiferentes quer à comunidade científica, quer à comunidade profissional. A formação de médicos e de boticários em Portugal não fugiu, também, a esta acção reformista.

Com a reforma pombalina da Universidade deu-se um aumento do número de Faculdades existentes: de quatro passaram para seis. Às Faculdades de Teologia, de Leis, de Cânones e de Medicina juntaram-se as Faculdades de Filosofia e de Matemática. Assim, a Universidade de Coimbra que comportava na sua maioria Faculdades das "ciências positivas» e apenas uma única Faculdade do âmbito das "ciências naturais» (Faculdade de Medicina), passou a consagrar, a partir de 1772, igual número Faculdades "positivas» e de "ciências naturais e filosóficas". Além da fundação destes estabelecimentos científicos foram instituídos com a reforma pombalina da Universidade outros locais destinados à investigação e ao apoio ao ensino. Assim, foram criados o Hospital Escolar, o Teatro Anatómico, o Dispensatório Farmacêutico, o Gabinete de História Natural, o Gabinete de Física Experimental, o Laboratório Químico, o Jardim Botânico e o Observatório Astronómico. Todos esses estabelecimentos eram do domínio das ciências naturais e filosóficas. Esta preferência pelas ciências experimentais na «nova 
fundação» da Universidade é, de facto, uma das grandes características da reforma pombalina da Universidade.

Neste trabalho vamos reportar-nos a alguns dos aspectos mais relevantes da formação de médicos e de boticários instituída pela reforma pombalina. Será oportuno dizer, desde logo, que Pombal se confrontou com dois problemas, a nosso ver da maior importância. Em primeiro lugar, conseguir espaços para albergar todos os estabelecimentos referidos e destinados ao ensino e à investigação; em segundo lugar, conseguir professores que ministrassem as matérias científicas de maior actualidade. No caso da Faculdade de Medicina será pertinente referir que o seu corpo docente foi afastado aquando da reforma de Pombal o que levantou dificuldades no preenchimento do quadro de docentes.

Assim, para dar resposta às duas questões anteriores, de facto determinantes para uma afirmação básica do projecto pombalino, Sebastião José de Carvalho e Melo tomou medidas decisivas. Por Carta Régia de 11 de Outubro de 1772 foram colocados à disposição da Universidade os edifícios do antigo Colégio das Onze Mil Virgens, pertença da Companhia de Jesus até à sua expulsão de Portugal. Aquelas instalações depois das devidas obras de adaptação foram destinadas a acolher diversos estabelecimentos da Universidade de Coimbra. Nelas foram instalados o Hospital Escolar, o Teatro Anatómico, o Dispensatório Farmacêutico directamente relacionados com a Faculdade de Medicina e, ainda, Gabinete de Historia Natural e o Gabinete de Física Experimental.

No que respeita ao segundo problema, atendendo a que a reforma pombalina instituiu novos cursos e novas disciplinas no ensino universitário, o Marquês de Pombal viu-se confrontado, como referimos, com o preenchimento de alguns lugares no corpo docente da instituição. O recurso a professores estrangeiros foi uma das medidas adoptadas, tendo sido tomada esta resolução porque, por um lado, tinha de ocupar os lugares existentes nas novas cadeiras das novas Faculdades e para os quais em Portugal não existia gente suficientemente qualificada para o fazer; por outro lado, 
porque após a expulsão dos padres jesuítas, o corpo docente português viu-se significativamente reduzido pois a Companhia de Jesus preenchia um grande espaço no ensino português. No caso concreto da Faculdade de Medicina a onde renovadora do Marquês de Pombal determinou que se jubilasse todo o corpo da Faculdade, tendo essa onda de afastamentos chegado a todas as Faculdades existentes. Estas medidas acentuaram ainda mais o recurso a pessoal estrangeiro para a Universidade como solução adoptada para ocupar lugares em aberto.

Retenhamo-nos no caso da Faculdade de Medicina. Neste estabelecimento, Simão Gold e Luis Cichi foram os dois lentes estrangeiros que para ali vieram leccionar. Para as outras Faculdades das ciências exactas e naturais, Filosofia e Matemática, vieram, também, outros lentes estrangeiros. Todos eles eram italianos à excepção de Gold. Contudo, todos estes lentes já haviam desempenhado, entre nós portugueses, funções profissionais. Não foram contratados especificamente e pela primeira vez para virem até Portugal e aqui integrarem o corpo docente universitário. Deles houve, de facto, um aproveitamento científico da sua permanência em Portugal.

Gold era médico na cidade do Porto. Foi contratado por causa da boa reputação que conseguiu enquanto clínico. A sua passagem pela Universidade de Coimbra foi curta e, possivelmente, pouco proveitosa. Faleceu em 1776 quando a reforma pombalina ainda estava a dar os seus primeiros passos e isto ainda se acentua mais se pensarmos que só até 1773 exerceu as suas funções académicas pois a partir daquele ano aposentou-se. Cichi era igualmente médico na cidade do Porto. Foi contratado para a Universidade de Coimbra para lente de anatomia na Faculdade de Medicina. A sua competência como clínico esteve na base da sua contratação. Descontente com o vencimento com que foi contratado para a Universidade, Cichi pediu aumento dos seus honorários. Este aumento foi-lhe concedido. Porém, a partir de 1774 , iniciaram-se as incompatibilidades entre Cichi e as autoridades universitárias desencadeando este processo a repreensão do professor, acabando toda esta questão com a sua demissão e o seu regresso a Itália 
em 1779. Foi precisamente neste ano que o Hospital Escolar iniciou o seu funcionamento, bem como o Dispensatório Farmacêutico. Entre 1772 e 1779

foi o Hospital Real, sito na parte baixa da cidade, que garantiu o ensino da prática aos alunos de medicina. Para o fornecimento de medicamentos houve recurso a boticários estabelecidos na cidade. Inicialmente a lotação do novo Hospital era de 68 camas e, volvidos aproximadamente trinta anos comportava 120 !

No caso concreto de Gold e Cichi, podemos adiantar que os resultados da sua permanência na Universidade de Coimbra não corresponderam ao que deles se esperava. Se é certo que as suas presenças na Universidade se fizeram sentir numa época em que, do ponto de vista institucional, muito ainda se encontrava por fazer, também é certo que não nos surgem resultados visíveis do seu trabalho na Faculdade de Medicina de Coimbra.

Outra opção eventualmente a tomar pelo Marquês de Pombal para conseguir um renovado corpo docente na Universidade de Coimbra, nomeadamente na Faculdade de Medicina, foi a formação de portugueses no estrangeiro junto de escolas de reconhecida reputação. Assim, após algum tempo de permanência junto dos melhores cientistas e clínicos estrangeiros os enviados de Pombal regressariam para incorporar o corpo docente da Universidade. De resto esta era a política preconizada pela Junta de Providência Literária e inscrita no Compêndio Histórico do Estado da Universidade de Coimbra de acordo com as recomendações de Jacob de Castro Sarmento, português residente em Inglaterra. Nessas recomendações sugeria-se, então, que, paralelamente à tradução das melhores e mais conceituadas obras de medicina, se «mandassem estudantes fora do reino fazerem-se peritos nas mesmas ciências, para virem depois ensiná-las, e propagá-las aos seus Nacionais» (p. 345). Ribeiro Sanches comungava também desta opinião conforme se pode verificar através do Metodo para Aprender e Estudar a Medicina. Mas, a verdade é que do corpo docente inicial da Faculdade de Medicina, dos quatro lentes titulares de cátedras que integraram o corpo docente da Faculdade em 1772, apenas um deles seguiu estes trilhos: José 
Francisco Leal. Este lente trabalhou junto de Van Swieten e pode-se considerar, também por isso, um discípulo da escola boerhaaviana. Em 1772, além dos dois lentes estrangeiros referidos e, ainda, de Leal, a Faculdade comportava entre lentes e demonstradores: António José Pereira (lente de Instituições Médico- Cirúrgicas), Manuel António Sobral (lente substituto) e José Correia Picanço (demonstrador de Anatomia). Em 1772, estavam por preencher os lugares de lente da Segunda Cadeira de Prática, de lente de Aforismos, o de segundo lente substituto e, ainda, de demonstrador de Matéria Médica.

Após 1772 a Faculdade tinha a seu cargo a investigação e o ensino da ciência médica conducente à formação de profissionais. Contudo, esta Faculdade tinha sobre si a responsabilidade de formar dois grupos distintos de profissionais: médicos e boticários. Os primeiros frequentavam o curso geral instituído pela reforma pombalina da Universidade obtendo a sua graduação passados cinco ou seis anos do curso, consoante se sujeitassem ou não a doutoramento; os segundos, os boticários, tinham a sua formação em instalações dependentes da Faculdade de Medicina no recém-instituído Dispensatório Farmacêutico do igualmente recém-formado Hospital Escolar. O curso de boticários era ministrado fundamentalmente pela prática, sendo remetida para plano secundário a componente teórica. Não conduzia a qualquer grau ou habilitação universitária superior e era ministrado dentro da dinâmica do curso médico. A formação de boticários encontrava-se articulada com a cátedra de Matéria Médica, disciplina fundada pela reforma pombalina e pertencente ao primeiro ano do curso médico, imediatamente após a institucionalização da reforma. Esta disciplina ensinava, também, a "Arte Farmacêutica». O curso de boticários tinha a duração de quatro anos. Nos dois primeiros anos os alunos inscreviam-se no Laboratório Químico e praticavam as operações químicas durante dois anos. Após este tempo de prática química os futuros boticários inscreviam-se no Dispensatório Farmacêutico e aqui praticavam as operações farmacêuticas durante outros dois anos. Depois destes quatro anos de ensino, os alunos sujeitavam-se 
a um exame feito perante o lente de Matéria Médica, seu demonstrador e o boticário do Dispensatório que se encarregava do questionário. Sendo considerado apto podia exercer a profissão em qualquer parte do país.

Do ponto de vista doutrinal encontramos um denominador comum nos estatutos médicos da Universidade de Coimbra: a referência contínua ao estado em que se encontrava a medicina portuguesa setecentista, um anti-galenismo sistemático e a sempre valorização do espírito experimental. Este posicionamento teórico não é surpreendente não só pelo facto da renovação que se pretendia dar à Faculdade de Medicina de Coimbra se processar em pleno século das luzes, mas, também, porque os elementos que tiveram influência decisiva no texto da reforma eram, na sua maioria, estrangeirados que pretendiam transportar para Portugal, mais concretamente para a Faculdade de Medicina, o espírito iluminista e as mais consagradas doutrinas médicas, com forte influência da escola boerhaaviana. Luís António Verney, Ribeiro Sanches, Castro Sarmento e Sachetti Barbosa são quatro nomes que se devem apontar como os que mais influenciaram o Marquês de Pombal na elaboração dos novos Estatutos médicos. Tanto quanto se sabe, Sachetti foi o elemento que mais actividade teve na execução do texto final; Ribeiro Sanches foi o elemento que do ponto de vista teórico mais influenciou a execução daqueles Estatutos.

Ribeiro Sanches foi discípulo directo da Boerhaave. Trabalhou junto do mestre holandês e bastaria esta referência para se deduzir que a forte influência iatromecânica se fez sentir na obra de Sanches. No que concerne à sua produção científica, deve ser valorizado no contexto das influências que se fizeram sentir sobre as ideias reformistas o Metodo para aprender $e$ estudar a Medicina, obra escrita em 1763, antes do trabalho de avaliação da Universidade que a Junta de Providência Literária teve a seu cargo.

A transformação sofrida pelo curso de medicina conferiu-lhe uma organização inteiramente nova. Através dos Estatutos da Universidade de Coimbra (1772) apercebemo-nos precisamente da nova dinâmica que se pretendia instituir à ciência médica portuguesa bem como à formação de médicos e, consequentemente, de boticários. 
O acesso à profissão médica e à arte de boticário, que até então estava limitado a cristãos-velhos, foi alterado. Os novos Estatutos não conferiam qualquer distinção entre cristãos-velhos e cristãos novos no que concerne ao direito de acesso à formação científica e profissional médico-farmacêutica sendo esta regra extensiva à ocupação de cargos públicos por parte daqueles que haviam sido perseguidos pela Inquisição, ou também os seus descendentes. A regra que os textos oficiais anteriores impunham como condição básica para o acesso a qualquer uma daquelas vias profissionais não existe nos Estatutos pombalinos, que anularam todos os textos oficiais sobre esse condicionamento.

Estipulava-se nos Estatutos universitários de 1772 que para a entrada no curso de medicina eram necessárias determinadas condições de ingresso. Por um lado, habilitações literárias mínimas; por outro lado, condições etárias. O curso tinha uma duração de cinco anos. Estes cinco anos habilitavam automaticamente para o exercício da medicina. A frequência de mais um ano do curso em determinadas condições específicas eram conducentes ao grau de doutoramento.

Estabelecia a reforma pombalina dos estudos médicos que o curso tivesse a duração de Outubro a Junho. Reservava-se para exames o mês de Julho e para férias os meses de Agosto e de Setembro. Assentava-se, ainda, que existisse um certo número de partidos para os estudantes de medicina (24) e para boticários (10) para que os alunos melhor habilitados, e que se distinguissem no decurso da sua formação científica, fossem recompensados.

Nos Estatutos da Universidade de Coimbra (1772) podemos, logo à partida, distinguir duas partes: por um lado, os estudos preparatórios; por outro lado, os estudos médicos propriamente ditos. Os estudos preparatórios para medicina tinham a duração de três anos. Das disciplinas preparatórias, tanto as línguas como a filosofia poderiam ser feitas fora da Universidade. Contudo, no que respeita à física e à matemática, era obrigatória a frequência daquelas disciplinas preliminares na Universidade de Coimbra. Justificava-se o ensino das línguas latina e grega para que os alunos ficassem conhece- 
dores das línguas em que se escreviam textos da especialidade e em que tem origem grande parte da terminologia médica. Além das línguas grega e latina era recomendável, com carácter não obrigatório, que os estudantes de medicina fossem também conhecedores de outras línguas muito comuns na Europa, nomeadamente línguas faladas com frequência e línguas vulgares em tratados médicos contemporâneos, casos do francês e do inglês.

No que respeita aos estudos de matemática e de física havia a obrigatoriedade de eles serem frequentados na Universidade de Coimbra, contrariamente com o que acontecia com as línguas. Na verdade, esta posição não nos admira já que era na Universidade que se pretendia estimular o desenvolvimento destas áreas das ciências exactas e experimentais. Aliás, fora da instituição Universitária, excluída que estava também a hipótese do Real Colégio dos Nobres, não existia nenhum outro estabelecimento científico vocacionado para as ciências experimentais e exactas.

Após estes estudos preparatórios, depois da respectiva aprovação, os estudantes estavam aptos a poderem matricular-se no curso de medicina. Este constava de cinco anos, findos os quais, os jovens médicos, depois de aprovados, ficavam habilitados a exercer a medicina. Ficavam aptos para o exercício total da profissão em qualquer lugar, fosse ele hospital, partido ou outro. Após 1772, o curso de medicina integrava as seguintes disciplinas: Matéria Médica e Farmácia ( $1^{\circ}$ Ano); Anatomia, Prática de Operações Cirúrgicas e Arte Obstetrícia (2 Ano); Instituições Médico-Cirúrgicas ( $3^{\circ}$ Ano); Aforismos ( $4^{\circ}$ Ano); Primeira Cadeira de Prática (5 Ano) e Segunda Cadeira de Prática ( $6^{\circ}$ Ano). Isto é: seis disciplinas para seis anos de curso.

Havia, portanto, seis disciplinas que estavam reservadas para seis lentes diferentes. Estipulava-se que as lições teriam uma duração de uma hora e meia e o seu horário seria repartido entre a manhã e a tarde.

As disciplinas do curso médico eram constituídas, na sua maioria, por uma componente prática e, ainda, por uma componente teórica. Nalgumas delas, nomeadamente na Matéria Médica, na Anatomia, bem como nas cadeiras de Prática, o ensino prático era muito valorizado. As cadeiras de 
Instituições Médico-Cirúrgicas e de Aforismos eram as disciplinas maioritariamente teóricas, aquelas mesmo que constituíam o grande suporte doutrinal e teórico do curso.

As aulas teóricas eram ministradas nos gerais da Universidade, sendo as aulas práticas repartidas pelos diferentes estabelecimentos preconizados pela reforma de 1772. À Matéria Médica e Farmácia estava destinado o ensino no Laboratório Químico, no Jardim Botânico e no Dispensatório Farmacêutico, este último vocacionado especificamente à preparação de medicamentos. O Teatro Anatómico apoiava as aulas de Anatomia, sendo as restantes disciplinas clínicas suportadas, na prática, pelo Hospital Escolar.

Cada cátedra era, por vezes, constituída por um quadro de disciplinas científicas cujo número não era normalizado e que era, evidentemente, adaptado de acordo com as necessidades do curso médico.

A cátedra de Matéria Médica e Arte Farmacêutica, pertencente ao $1^{\circ}$ ano, compreendia o estudo das matérias-primas necessárias à preparação dos medicamentos e também o estudo das técnicas necessárias para a preparação desses mesmos medicamentos; era esta última parte, a que se reservava mais à prática farmacêutica, isto é, a que se destinava a ser maioritariamente o objecto das aulas práticas.

$\mathrm{Na}$ Anatomia, disciplina do $2^{\circ}$ ano, determinava-se estudar o corpo humano, cabendo às aulas práticas desta cátedra a prática de operações cirúrgicas bem como de determinadas operações ou técnica obstetrícias.

No $3^{\circ}$ ano a disciplina de Instituições Médico-Cirúrgicas congregava o estudo da fisiologia, da patologia, da semiótica, da higiene e da terapêutica. Como complemento os alunos iniciavam a sua prática geral de medicina e de cirurgia no Hospital Escolar.

No que concerne ao $4^{\circ}$ ano, isto é, à cadeira de Aforismos, onde se estudavam os aforismos de Hipócrates e de Boerhaave, o aluno tinha como complemento, também, a prática hospitalar.

E, aos dois últimos anos, cabia inteiramente a prática hospitalar. Como dissemos, o $6^{\circ}$ ano do curso, ano de graduação, revestia-se de características 
excepcionais, sendo considerado um ano conducente a graus superiores, onde além da prática o aluno deveria repetir as disciplinas do $3^{\circ}$ ano e do $4^{\circ}$ ano.

No capítulo concernente à Faculdade de Medicina, temos como denominador comum a influência da escola boerhaaviana na redacção dos estatutos médicos de 1772. Subjacente a todo o texto, algumas vezes de uma maneira clara, outras vezes de um modo mais discreto, encontramos referências nítidas a posições iatromecânicas, sem dúvida, um dos sérios baluartes da escola holandesa. São diversas as passagens dos Estatutos de 1772 que nos atestam o que acabámos de referir. Ao falarem do estudo da anatomia, os legisladores reportam-se precisamente à «f́́brica, e mecanismo do mesmo corpo» (p. 35). Ao referirem-se às lições do $3^{\circ}$ ano, os Estatutos adiantam que depois dos alunos terem aprendido os conceitos do primeiro e do segundo ano, estão em condições de estudar a teoria da medicina devidamente conjugada com os princípios da física e da matemática. Ao reportarem-se às lições do $4^{\circ}$ ano, mais concretamente, ao referirem-se às explicações dos aforismos de Hipócrates, os Estatutos indicam que a sua explicação deveria ser sustentada nos comentários feitos por Van Swieten e por outros autores da escola de Boerhaave. Contudo, nesta parte do texto fica bastante claro o posicionamento dos legisladores ao adiantarem que, embora naquele tempo se indicasse como suporte teórico fundamental as concepções de Boerhaave, isto não implicava que a doutrina do clínico holandês prevalecesse indefinidamente no ensino médico. Muito pelo contrário: a posição dos Estatutos era, precisamente, a de que o ensino e a investigação científica representam mudança e que também a dimensão que Boerhaave dava à medicina poderia ser ultrapassada. Contudo, o processo de sucessão deveria ser criterioso. Por isso adiantava-se o seguinte: «que não mudem facilmente de Boerhaave para outro, sem ponderarem, e discutirem por miúdo as vantagens, que disso podem resultar: E tanto que julgarem, que pode haver alguma vantagem na dita mudança sem inconveniente, que a destrua, não deixem de a fazer; pondo de parte toda paixão, e parcialidade» (p. 60). 
Os Estatutos de 1772 estabeleceram uma hierarquia entre as cadeiras. As consideradas disciplinas menores eram precisamente as dos dois primeiros anos, isto é: a Matéria Médica e Arte Farmêutica e a Anatomia. As restantes quatro cadeiras, isto é, Instituições Médico-Cirúrgicas, Aforismos, e as duas Cadeiras de Prática, eram consideradas as cadeiras maiores.

As cátedras dos dois primeiros anos, Matéria Médica e Anatomia, eram consideradas como conceitos básicos, como disciplinas preparatórias das disciplinas maiores. Era indispensável ao médico o conhecimento da anatomia para que depois se pudesse instruir com maior profundidade nas outras disciplinas e na prática clínica; era necessário ao médico o conhecimento das matérias-primas necessárias à preparação dos medicamentos, bem como o conhecimento das técnicas necessárias à preparação desses mesmos medicamentos. Essas disciplinas tinham, então, por obrigação dar os fundamentos gerais necessários à afirmação científica das grandes áreas médicas. Era neste sentido que eram consideradas menores. Menores porque não constituíam o mais genuíno campo doutrinal da medicina; porque eram disciplinas que correspondiam a interesses profissionais de outros estratos que não, exclusivamente, os médicos; porque se tratava de disciplinas que eram muito vocacionadas para uma carga prática demasiado acentuada e porque grandes reflexões teóricas não teriam até então grande lugar nesses domínios.

A anatomia seria fundamental para o entendimento da fisiologia e da patologia, porque era evidente que sem o perfeito conhecimento do corpo humano, das suas partes, bem como do seu funcionamento, era impossível a compreensão dos estados patológicos.

Por seu turno, a matéria médica e as matérias de índole farmacêutica eram imprescindíveis para o estudo da terapêutica. Sem o conhecimento das matérias-primas necessárias à preparação de medicamentos, sem o conhecimento das suas virtudes medicinais e sem se conhecer o modo de preparação dos medicamentos, era praticamente impossível instituir uma correcta terapêutica ou até mesmo preparar alguns medicamentos. 
Embora Sanches e Verney tenham preconizado para os estudos médicos o ensino da anatomia no primeiro ano, o certo é que em Coimbra, na Faculdade de Medicina, essa cadeira não foi instituída logo no ano inaugural do curso. Só mais tarde, no ano-lectivo de 1791/92, os estudos anatómicos passaram para o $1^{\circ}$ ano, avançando a cátedra de Matéria Médica para o $3^{\circ}$ ano do curso de medicina.

O tratamento dispensado a estas duas disciplinas médicas, Matéria Médica e Anatomia, ao longo dos Estatutos de 1772 é também representativo do modo como as profissões de boticário e de cirurgião eram consideradas no domínio das ciências da saúde. Mais: o modo como as disciplinas estavam enquadradas no curso, bem como o tratamento que elas mereceram por parte dos legisladores são, igualmente, tradutores da afirmação que aqueles dois estratos profissionais tinham no contexto da política profissional e do peso dos respectivos grupos profissionais.

Nos Estatutos de 1772, a farmácia e a cirurgia foram tratadas de modo distinto. Ambas eram consideradas, até então, como disciplinas menores, ambas eram consideradas como matérias científicas base para a formação do médico. Enquanto disciplinas científicas elas encontravam-se dentro dos grandes limites da medicina, do ponto de vista profissional havia alguma divergência. À medicina, propriamente dita, destinada ao diagnóstico e à terapêutica, destinava-se o médico enquanto profissional de uma arte doutrinal. À cirurgia e à farmácia, embora consideradas como áreas do campo médico, corresponderia um exercício profissional fundamentalmente vocacionado para a prática, sendo, por isso mesmo, consideradas artes mecânicas. Todo o grande corpo doutrinal da medicina era preenchido pelas questões relacionadas com a fisiologia, a patologia e a terapêutica; de algum modo, o correspondente à cátedra de Instituições Médico Cirúrgicas instituída na Faculdade de Medicina após 1772. As outras disciplinas científicas, a matéria médica e a farmácia, bem como a anatomia representavam um suporte mais técnico do que propriamente científico para a resolução de determinados problemas médicos. E, também por isso, deviam existir 
dois grupos profissionais distintos dos médicos, encarregados de uma actividade fundamentalmente prática, estando remetida para plano secundário a componente teórica.

Nos estatutos de 1772, a farmácia é, de facto admitida como área necessária à formação do médico; para a cirurgia faz-se igual atribuição. Mas, enquanto se reconhece que, do ponto de vista profissional, medicina e cirurgia sejam um corpo único, nada se adianta no que concerne à farmácia. Esta integração profissional da cirurgia dentro do campo médico se por um lado elevava o estatuto científico daquela disciplina médica, por outro lado, limitava-lhe a hipótese de se autonomizar. Por isso os Estatutos da Universidade de 1772 adiantavam claramente: «que o divórcio entre a Medicina e Cirurgia tem sido mais do que todas as outras causas prejudicial aos progressos da Arte de curar, e funesto à vida dos homens; não sendo possível que seja bom Médico, quem não fôr ao mesmo tempo Cirurgião, e reciprocamente. Ordeno outro sim, que o Estudo da Cirurgia prática e especulativa acompanhe sempre o da Medicina; e que daqui por diante sejam todos os Médicos ao mesmo tempo Cirurgiões, passando-se-lhe as suas Cartas com a declaração de uma, e outra coisa, sobre os Actos, e Exames, que delas hão-de fazer» (p. 20).

Para a cirurgia reservava-se um estatuto profissional idêntico ao da medicina geral ou, como se referia, pretendia-se que a cirurgia tivesse «a mesma graduação, e nobreza" do que a "Medicina interna» (p. 20). Esta posição já tinha sido assumida por Francisco de Lemos ao adiantar na sua Relação Geral do Estado da Universidade (1777), que ao congregar teoria e prática a medicina não deveria ser distinta da cirurgia (p. 67). Esta opinião foi, igualmente, partilhada por Caetano José Pinto de Almeida ao inscrever nos Primeiros Elementos de Cirurgia e Therapeutica, que a cirurgia é parte integrante da medicina. Contudo, perante os Estatutos de 1772 este posicionamento não implicava que os cirurgiões ou sangradores sem estudos universitários fossem elevados ao estatuto profissional de médicos. Estes, por falta de estudos adequados, não eram considerados médicos. 
De resto, a fundação da Régia Escola de Cirurgia em 1825, e das Escolas Médico-Cirúrgicas em Lisboa e no Porto em 1836, reflecte este sentido de maior valorização da cirurgia no seio da família médica do que propriamente da farmácia. As Escolas Régias de Cirurgia nascem onze anos antes de se fundarem as Escolas de Farmácia em Coimbra, Lisboa e Porto, em 1836, precisamente anexas à Faculdade de Medicina de Coimbra, bem como às igualmente recém-instituídas Escolas Médico Cirúrgicas.

No que diz respeito aos exames e à avaliação dos alunos de medicina os Estatutos de 1772 dedicam o Título V da Parte I, intitulado "Dos Exames, Actos e Graus». Anualmente, os alunos eram obrigados a prestar provas de avaliação. E, consoante fossem considerados aptos ou não, assim se verificava ou não a sua transição para o ano seguinte. Ao obterem aprovação no $4^{\circ}$ ano do curso atingiam o primeiro grau: o de bacharel. Este correspondia ao primeiro grau a que o aluno de medicina poderia aspirar. Contudo, este grau não lhe dava poderes para exercer a medicina. Consistia num grau puramente académico e sem qualquer representatividade a nível profissional. A obtenção de um estatuto profissionalizante só era atingido um ano depois, no $5^{\circ}$ ano. Os que concluíssem com êxito o $5^{\circ}$ ano eram considerados bacharéis formados em medicina, podendo exercer a medicina ou cirurgia em qualquer ponto do país. Não sendo considerados aprovados nesta disciplina os alunos tinham a possibilidade de repetir o respectivo exame, não podendo reprovar mais do que duas vezes. Três reprovações eram sinónimo de que o acesso ao exercício da medicina estava impedido. Caso isto acontecesse determinava-se que o aluno não se poderia sujeitar a novo exame e era considerado inapto para o exercício da medicina. Os exames deste ano de formatura, isto é, do $5^{\circ}$ ano, correspondiam aos designados "Actos Pequenos», em contraposição com os «Actos Grandes», isto é, os exames conducentes ao doutoramento.

Se as habilitações anteriores davam grande ênfase à formação prática nunca descurando, evidentemente a formação teórica, nos exames do $6^{\circ}$ ano acontecia o inverso. Isto é: dava-se mais destaque à formação teórica. 
Enquanto que o $5^{\circ}$ ano formava médicos para o exercício da prática clínica, o $6^{\circ}$ ano destinava-se a formar médicos para o magistério e que já haviam adquirido a suficiente formação prática.

Deste modo podemos distinguir dois tipos de habilitações académicas: por um lado, as necessárias para a prática da clínica médica; por outro lado, as que eram conducentes não só ao exercício da prática da medicina mas, fundamentalmente, ao ensino médico. No primeiro caso bastariam os primeiros cinco anos do curso. No segundo caso era necessária a frequência do $6^{\circ}$ ano do curso de medicina. A grande distinção reside, precisamente, na atenção dada à natureza teórica dos graduados. Se para os primeiros deveria prevalecer uma especial atenção pela prática, nos segundos, para que eles alcançassem os actos grandes, seria necessário além do domínio da prática, o perfeito conhecimento da teoria.

O $6^{\circ}$ ano do curso era considerado o "Ano de graduação", precisamente porque era conducente à obtenção de um grau académico superior. E, porque, nesse ano deveria ser dispensada maior atenção à parte teórica da medicina, os alunos teriam obrigatoriamente que se matricular nas disciplinas do $3^{\circ}$ ano e do $4^{\circ}$ ano aquelas que se encontravam recheadas do maior valor teórico e, por conseguinte, constituíam o mais forte núcleo doutrinal da medicina. Por isso, sobre estas disciplinas, adiantava-se nos Estatutos de 1772 que nelas «se contém a parte Teórica, e Doutrinal da Medicina» (p. 107). Facultativamente os alunos de medicina poderiam frequentar outras disciplinas do curso de acordo com o seu interesse numa maior ampliação dos seus conhecimentos científicos. Em qualquer dos casos recomendava-se que os lentes das respectivas cadeiras dessem especial atenção aos alunos do "Ano de graduação".

Após a frequência deste "Ano de graduação", os alunos estavam em condições de requerer o seu exame ao reitor da Universidade. Este exame denominava-se "Acto de Repetição» ou "Conclusões Magnas». Após estas provas os alunos sujeitavam-se ao "Exame Privado» para a obtenção do "Grau de Licenciado». Finalmente, depois de aprovados no «Exame Priva- 
do", os alunos faziam um requerimento ao reitor para lhes ser concedido o "Grau de doutor" depois de terem comprovado documentalmente a sua licenciatura.

Saliente-se, neste particular, da obtenção de graus superiores, que as provas respeitantes às Conclusões Magnas não correspondiam a uma única disciplina ou a um único assunto. A matéria em avaliação não era limitada apenas a uma só disciplina mas eram percorridas todas as disciplinas do curso. As matérias eram ordenadas ou organizadas «em forma de teses» não havendo lugar para a redacção de qualquer dissertação. As teses, escritas em latim, eram publicadas pela Imprensa da Universidade e estavam divididas em secções, tantas quantas as áreas científicas do curso de medicina. Esta prática suscitou interesse por parte de Link, aquando da sua digressão científica pelo nosso país. Ele referia que o doutoramento se destinava exclusivamente a quem quisesse seguir o magistério universitário e que os doutorandos não escreviam qualquer dissertação mas faziam, antes, a defesa de uma tese pública.

Constava a prestação destas provas de um exame público feito perante um júri presidido pelo lente do $4^{\circ}$ ano ou, no seu impedimento, pelo lente do $3^{\circ}$ ano. $\mathrm{O}$ «Exame Privado», correspondia a um interrogatório sobre assuntos das cadeiras do $3^{\circ}$ ano e do $4^{\circ}$ ano. O júri era presidido da mesma forma como estava instituído para as "Conclusões Magnas».

O ensino médico instituído pela reforma pombalina da Universidade manteve-se em moldes idênticos até 1836, ano em que a reforma de ensino de Passos Manuel organizou em novos moldes o ensino médico da Universidade de Coimbra. A introdução de um Hospital Escolar e de um Teatro Anatómico no ensino médico, no seguimento de uma política valorizadora do ensino experimental, bem como a introdução de disciplinas sintonizadas com a matriz boerhaaviana caracterizam a reforma dos estudos médicos. No que concerne ao ensino da farmácia, dois aspectos merecem, desde logo, a nossa especial atenção: em primeiro lugar a existência de um espaço entre os muros da Universidade para a formação de boticários, o Dispensatório 
Farmacêutico, e, em segundo lugar, a introdução da química na formação de boticários que apesar de ministrada de acordo com parâmetros unicamente práticos, permitia um contacto dos futuros boticários com as operações fundamentais da química lavoisieriana.

\section{BIBLIOGRAFIA E SUGESTÕES DE LEITURA}

ALMEIDA, M. Lopes de - Documentos da reforma Pombalina, 2 vols., Coimbra, Universidade, 1937-1979.

CARVAlHO, A. Silva - História da Medicina Portuguesa, Lisboa, Imprensa Nacional, 1929.

CUNHA, Guilherme de Barros e - «O ensino farmacêutico na Universidade de Coimbra. Sua criação e evolução até à reforma de Hintze Ribeiro (1902)", Notícias Farmacêuticas, Coimbra, 4(1-2) 1937, pp. 67-89.

DIAS, J. P. Sousa - «Instituições dedicadas ao ensino da farmácia em Portugal - uma perspectiva histórica", Farmácia Portuguesa; Lisboa, 11(53)1988, pp. 8-12.

D'ESAGUY, Augusto - Jacob de Castro Sarmento, Lisboa, Edições Ática, 1946.

GUERRA, Miller - "A reforma pombalina dos estudos médicos», in: Pombal revisitado, vol. 1, Lisboa, Editorial Estampa, 1984.

LEMOS, Francisco de - Relação geral do estado da Universidade (1777), Coimbra, Universidade, 1980 .

LEMOS, Maximiano - "Amigos de Ribeiro Sanches", in: Estudos de História da Medicina Peninsular, Porto, Tip. Enciclopédia Portuguesa, 1916, pp. 151-353.

LEMOS, Maximiano - História da Medicina em Portugal. Doutrinas e instituições, $2^{\mathrm{a}}$ ed., 2 vols., Lisboa, Publicações Dom Quixote/Ordem dos Médicos, 1991.

LEMOS, Maximiano - Ribeiro Sanches. A sua vida e a sua obra, Porto, Eduardo Tavares Martins, 1911.

MIRA, M. Ferreira de - História da Medicina Portuguesa, Lisboa, Empresa Nacional de Publicidade, 1947.

PITA, João Rui - "Breve história da Faculdade de Farmácia da Universidade de Coimbra - uma perspectiva científico profissional", Munda, 24, 1992, pp. 3-16.

PITA, João Rui - «Dispensatório Farmacêutico - a Botica do Hospital da Universidade. Subsídios para a sua história", in: Universidade(s) - História. Memória, Perspectivas. Actas do Congresso História da Universidade (No $7^{\circ}$ Centenário da sua fundação), Coimbra, Comissão Organizadora do Congresso "História da Universidade», vol. 2, 1990, pp. 11-19.

PITA. João Rui - "Dispensatório Farmacêutico. Subsídios para a sua história», Boletim da Faculdade de Farmácia de Coimbra, 11(1)1987, pp. 69-74

PITA, João Rui - "O ensino da Farmácia na reforma pombalina da Universidade de Coimbra», Kalliope - De Medicina, Coimbra, 1(2)1988, pp. 41-45.

PITA, João Rui - Farmácia, medicina e saúde pública (1772-1836), Coimbra, Minerva, 1996. 
PITA, João Rui - A farmácia em Portugal (1772-1836). Ciência, ensino e produção de medicamentos no Dispensatório Farmacêutico, 3 vols., Coimbra, Tese de doutoramento, 1995.

PITA, João Rui - "La farmacia en Portugal a finales del siglo XVIII", in: ACEVES PASTRANA, Patrícia, La quimica en Europa y America (siglos XVIII y XIX) - Estudios de historia social de las ciencias químicas y biológicas, México, Universidad Autónoma Metropolitana, 1994, pp. 69-92.

PITA, João Rui - «Notas sobre a fundação do Dispensatório Farmacêutico do Hospital da Universidade (1772)», Munda, 20, 1990, pp. 47-52.

SANCHES, António Nunes Ribeiro - "Apontamentos para estabelecerse hum Tribunal \& Collegio de Medicina na intençaõ que esta Sciencia se conservasse de tal modo, que sempre fosse util ao Reyno de Portugal, e dos seos Dilatados Dominios», in: Obras, vol. 2, Coimbra, Universidade, 1966, pp. 21-132.

SANCHES, António Nunes Ribeiro - "Cartas sobre a educaçaõ da mocidade (1760)», in: Obras, vol. 1, Coimbra, Universidade, 1959, pp. 201-366.

SANCHES, António Nunes Ribeiro - "Metodo para aprender e estudar a Medicina», in: Obras, vol. 2, Coimbra, Universidade, 1959, pp. 1-200.

SANCHES, António Nunes Ribeiro - Tratado da conservaçaõ da saude dos povos», in: Obras, vol. 2, Coimbra, Universidade, 1966, pp. 149-391.

SILVA, Pedro José da - História da Pharmacia Portugueza desde os primeiros séculos da monarchia até ao presente, 3 memórias, Lisboa, Tip. Franco-Portugueza, 1866-1868.

VERNEY, Luís António - Verdadeiro metodo de estudar, 2 vols., Valensa, Officina de Antonio Balle, 1746.

WILlEMSE, David - António Nunes Ribeiro Sanches - élève de Boerhaave - et son importance pour la Russie, Leiden, E. J. Brill, 1966. 